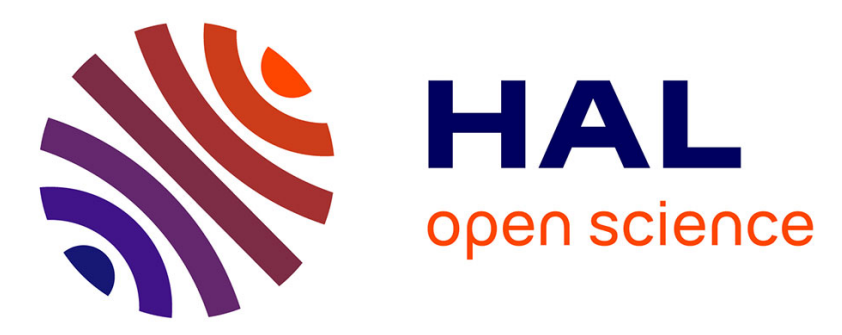

\title{
Glass-epoxy composite behaviour under shock loading
}

A. Zhuk, G. Kanel, A. Lash

\section{To cite this version:}

A. Zhuk, G. Kanel, A. Lash. Glass-epoxy composite behaviour under shock loading. Journal de Physique IV Proceedings, 1994, 04 (C8), pp.C8-403-C8-407. 10.1051/jp4:1994862 . jpa-00253422

\section{HAL Id: jpa-00253422 https://hal.science/jpa-00253422}

Submitted on 1 Jan 1994

HAL is a multi-disciplinary open access archive for the deposit and dissemination of scientific research documents, whether they are published or not. The documents may come from teaching and research institutions in France or abroad, or from public or private research centers.
L'archive ouverte pluridisciplinaire HAL, est destinée au dépôt et à la diffusion de documents scientifiques de niveau recherche, publiés ou non, émanant des établissements d'enseignement et de recherche français ou étrangers, des laboratoires publics ou privés. 


\title{
Glass-epoxy composite behaviour under shock loading
}

\author{
A.Z. Zhuk, G.I. Kanel and A.A. Lash \\ High Energy Density Research Centre, Russian Academy of Sciences (IVTAN), Izhorskaya 13/19, \\ Moscow 127412, Russia
}

\begin{abstract}
Shock compressibility and sound velocity in commercial fibre-glass at pressures up to $22 \mathrm{GPa}$ were studied using manganin gauges. Free surface wave profiles were measured by Doppler velocity interferometry at pressures of about $1 \mathrm{GPa}$. Material spall strength and viscosity were evaluated.
\end{abstract}

\section{INTRODUCTION}

The dynamic response of composite materials to shock loading has been extensively studied because of the wide application of composites in rocket and space techhnology. Nevertheless there is a lack of experimental information concerning the spall strength of composite materials and their behaviour at moderate pulse pressures. Shock compressiblity of epoxy-based composites with $\mathrm{Al}$ and graphite fibre fillers has been explored [1,2]. Experimental Hugoniots were found to be in good agreement with calculations based on the rule of mixtures. Shock front dispersion was detected in Al-epoxy composite [1]. Other authors [3-5] have investigated shock compressibility and spall strength of epoxy-based composites with glass fabric and cloth fillers. Spall strength values of 0.1 to $0.3 \mathrm{GPa}$ were close to the spall strength of the pure matrix material. On the other hand, Tohkem and Erlich [6] studied the fragmentation of epoxy-kevlar fibre composite and obtained a spall strength value of about $0.05 \mathrm{GPa}$. In an investigation of epoxy-42 volume per cent. glass microballoons [7], Hugoniot and shock front structure were studied at 0.5 to $4.2 \mathrm{GPa}$ and the spall strength was found to be close to zero. Significant dispersion of the shock front was observed. The authors proposed that the dispersion was a result of the collapse of the pores and the crushing of the microballoons. $H$. Nahme et al. [8] investigated the dynamic behaviour of shock loaded $\mathrm{FeO}-\mathrm{SiO}_{2}$ composite material. The material was found to exhibit a low Hugoniot elastic limit, between 0.01 and $0.03 \mathrm{GPa}$, and a spall strength of less than $0.01 \mathrm{GPa}$. Microscopic and SEM examination of recovered samples showed that even at low impact velocities the material was damaged by local stresses which are caused by the internal structure of the material.

It is possible to conclude that there are are at least two features to the behaviour of composite materials under shock loading: i) a significant scattering, from $500 \mathrm{GPa}$ to $0.3 \mathrm{GPa}$, of spall strength 
values; ii) a complex structure of the shock front. The aim of the present study was to measure the dynamic compressibility, sound velocity and spall strength of a commercial plain-weave glassepoxy composite and to explore its shock front structure.

\section{EXPERIMENTAL}

Commercial plain-weave fibre-glass KAST-V (Soviet standard 102-92-74) consisting of epoxy resin VBF-1 matrix and glass fabric filler (Soviet standard 19170-73) was studied. Samples had an initial density of 1.78 to $1.80 \mathrm{~g} / \mathrm{cm}^{3}$. The loading direction was normal to the plane of the fabric layers.

Shock compressibility and sound speed velocity at pressures of $5-22 \mathrm{GPa}$ were measured using manganin gauges [9]. The samples were loaded by the impact of $\mathrm{Al}$ plates through an $\mathrm{Al}$ base plate. Plates were accelerated by high explosive generators. The first gauge was mounted in the interface between the base plate and the sample and another gauge was installed in the internal cross section of the sample. In order to decrease the influence of the sample roughness, the gauges were separated from the sample by teflon films of a thickness less than $0.09 \mathrm{~mm}$. Free surface velocity profiles at pressures of $0.8-1.2 \mathrm{GPa}$ were measured by means of the Doppler velocity interferometer - VISAR technique [10]. The samples were loaded by the impact of $\mathrm{Al}$ plates accelerated by a powder gun. To reflect the VISAR beam, $40 \mu \mathrm{m}$ thick Al foil was glued with epoxy adhesive to the free surface of the sample. Samples loaded at pressures from 0.8 to $7.6 \mathrm{GPa}$ were recovered. Experimental details are listed in Table I.

TABLE I Details of Experimental Set-Up

$\left(D_{i}, D_{S}\right.$ - impactor and screen thickness, respectively; $W$ - impactor velocity; $\ell$ - distance between manganin gauges)

\begin{tabular}{|c|c|c|c|}
\hline $\begin{array}{c}\mathrm{D}_{\mathrm{i}} \\
(\mathrm{mm})\end{array}$ & $\begin{array}{c}\mathrm{D}_{\mathrm{s}} \\
(\mathrm{mm})\end{array}$ & $\begin{array}{c}\ell \\
(\mathrm{mm})\end{array}$ & $\begin{array}{c}\mathrm{W} \\
(\mathrm{km} / \mathrm{s})\end{array}$ \\
\hline 4 & - & - & 0.2 \\
6.8 & - & - & 0.3 \\
4 & 3.95 & 4.75 & 1.5 \\
10 & 3.95 & 8.28 & 2.5 \\
3.9 & 3.95 & 4.75 & 3.8 \\
\hline
\end{tabular}

\section{RESULTS}

Typical pressure profiles are presented in fig. 1. Elastic precursor and elastic release waves were not observed. Since both profiles exhibit small rises in the pressure plateau, it is believed that the rise is not concerned with a relaxation process in the material but is the result of deformation of the gauges. Free surface velocity profiles were measured for different impactor thicknesses. Shock wave attenuation was observed at small impactor thicknesses. At impactor thicknesses from 2.5 to $6.8 \mathrm{~mm}$ the free surface velocity did not change under uniform loading conditions. Free surface velocity profiles are shown in fig. 2. A spall pulse is apparently not observed. The shock fronts exhibit an unusually long rise time of about 250ns. Shock wave parameters and sound velocity data are presented in Table II and fig. 3.

\section{DISCUSSION}

To calculate specific volume and loading-unloading trajectories for fibre-glass we used the pressure- 


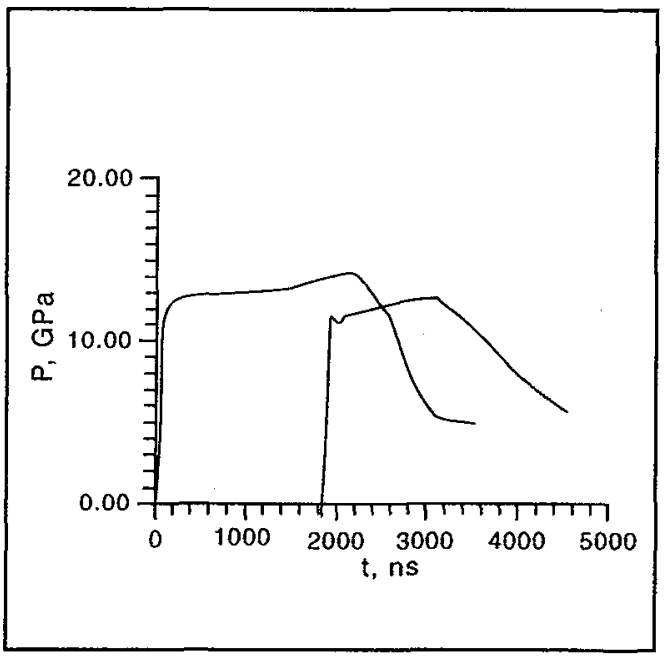

Fig. 1 Pressure vs. time profiles at 13.5GPa

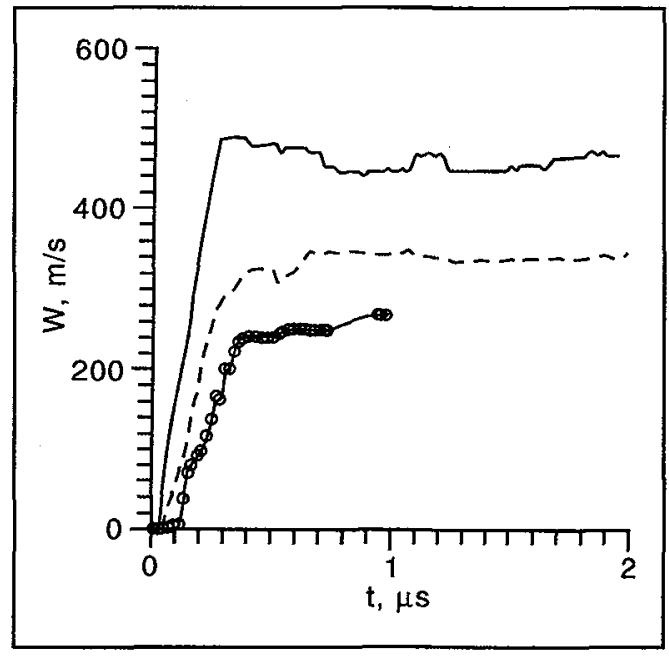

Fig. 2 Free surface velocity profiles at different impact velocities

(solid line $-320 \mathrm{~m} / \mathrm{s}$;

dashed line - $220 \mathrm{~m} / \mathrm{s}$, impactor thickness, $4 \mathrm{~mm}$; asterisks $-220 \mathrm{~m} / \mathrm{s}$, impactor thickness, $1.3 \mathrm{~mm}$ )

TABLE II Shock Wave Parameters

$\left(U_{S}\right.$ - shock wave velocity; $U_{P}$ - particle velocity; $P$ - pressure; V - specific volume; $C$ - Eulerian sound velocity)

\begin{tabular}{|c|c|c|c|c|c|}
\hline $\begin{array}{c}\mathrm{W} \\
(\mathrm{km} / \mathrm{s})\end{array}$ & $\begin{array}{c}\mathrm{P} \\
(\mathrm{GPa})\end{array}$ & $\begin{array}{c}\mathrm{U}_{\mathrm{s}} \\
(\mathrm{km} / \mathrm{s})\end{array}$ & $\begin{array}{c}\mathrm{U}_{\mathrm{P}} \\
(\mathrm{km} / \mathrm{s})\end{array}$ & $\begin{array}{c}\mathrm{C} \\
(\mathrm{km} / \mathrm{s})\end{array}$ & $\begin{array}{c}\mathrm{V} \\
\left(\mathrm{cm}^{3} / \mathrm{g}\right)\end{array}$ \\
\hline 0.2 & 0.9 & 3.07 & 0.16 & - & 0.532 \\
0.3 & 1.3 & 3.22 & 0.23 & - & 0.522 \\
1.5 & 7.6 & 4.00 & 1.06 & 4.65 & 0.411 \\
2.5 & 13.5 & 4.57 & 1.66 & 5.73 & 0.357 \\
3.9 & 21.6 & 5.67 & 2.13 & 6.96 & 0.349 \\
\hline
\end{tabular}

time profiles and the simple wave approximation:

$$
\mathrm{d} \mathbf{V}=-\mathrm{dP} /\left(\mathbf{R}_{\mathrm{o}}\right)^{2} \boldsymbol{a}^{2}
$$

where $\mathrm{dV}$ and $\mathrm{dP}$ are volume and pressure increments, $\mathbf{R}_{\mathbf{o}}$ is the initial material density and $\boldsymbol{a}$ is the Lagrangian phase velocity of perturbation. The release adiabat lies below the Hugoniot. It is the evidence that significant deviatoric stresses exist in the material during the loading-unloading cycle.

If the rise time of the shock front and the Hugoniot for the material are known one may evaluate the shear viscosity, $n=T / \dot{e}$, where $T$, the shear stress in a steady shock wave, is determined from the deviation between the straight line connecting the initial and final states of the material and the Hugoniot and $\dot{e}$, the deformation rate, was determined from the equation, $\dot{\mathbf{e}}=\left[\ln \left(\mathbf{V} / \mathbf{V}_{\mathrm{o}}\right)\right] / \mathbf{t}$, where 


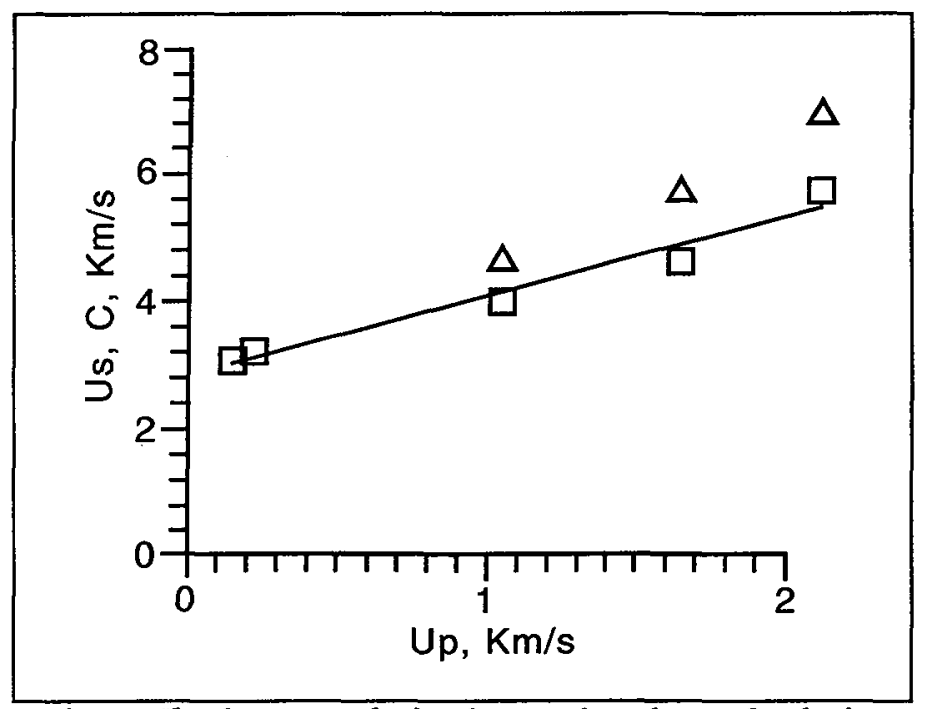

Fig. 3 Shock wave velocity (squares) and sound velocity (triangles) vs. particle velocity

$t$ is the rise time and $V_{0}=1 / R_{0}$. We take the shock compressibility data as an approximation to the Hugoniot for fibre-glass. The viscosity appeared to be about $100 \mathrm{~Pa}$.s at a deformation rate of about $0.24 \times 10^{6} \mathrm{~s}^{-1}$. The fibre-glass shear viscosity is higher than that for metals but lower than the usual viscosity of polymers [11].

Examination of recovered samples showed that fragmentation mainly occurs in matrix layers. Samples recovered after shock loading at pressures less than $1.5 \mathrm{GPa}$ consisted of undamaged glass layers separated by strongly damaged epoxy layers. Since a spall pulse was apparently not observed we suggest that the spall strength of fibre-glass KAST-V is less than the measurement resolution. Nevertheless it is possible to evaluate the upper limit of the dynamic tensile strength of the material. The velocity measurement resolution was about $7-10 \mathrm{~m} / \mathrm{s}$. We used the known relation for spall strength, $S$, and free surface velocity change, $(d w)$,

$$
\mathbf{S}=1 / 2 \mathbf{C}_{\mathbf{o}} \mathbf{R}_{\mathbf{o}}(\mathrm{d} \mathbf{W})
$$

and assume that the upper limit on the magnitude of the spall pulse corresponds to the resolution of the velocity measurement, i.e. we take $(\mathrm{dW})=10 \mathrm{~m} / \mathrm{s}$. The spall strength evaluated in this way appeared to be $0.02 \mathrm{GPa}$. The spall strength value for fibre-glass KAST-V is in good agreement with other data $[6,8]$ and with results of static tests [12], but is significantly lower than the spall strength determined in [5]. The final state of the recovered samples in [5] was examined and it is clear that the formation of the macrocracks observed in these samples demands a higher tensile stress and more time than are required for the initiation of failure.

We propose that the low spall strength of fibre-glass, as well as the strong shock front dispersion, is a result of wave reflection between components with different shock impedances and of matrix destruction during compression. Destruction is initiated by shear stresses arising at the uneven contact surface between the epoxy matrix and the coarse-weave glass fabric.[8]. In spite of the planar structure of KAST-V, it behaves as a composite with a random distribution of filler particles [7] and does not exhibit the multi-step structure observed in the case of model planar composites [13]. 


\section{REFERENCES}

1. Holms B.S. and Tsou F.K., J. Appl. Phys. 43 (1972) 957-961.

2. Bushman A.V., Efremov V.P., Kanel G.I. et al., (Sov.) J. Chem. Phys. 11 (1992) 410-414.

3. Butkov Yu.B., Novikov S.A. and Sinitsina L.M., (Sov.) Mekhanika Kompositsionnich Materialov 2 (1979) 97-102.

4. Astatnin V.V. and Romanchenko V.I., (Sov.) Mechanika Kompositsionnich Materialov 4 (1984) $731-734$.

5. Golubev V.K., Novikov S.A. and Sobolev Ju.S., (Sov.) J. Prikladnoj Mech. and Tech. Fiziki., 6 (1987) 140-145.

6. Tokhem R.E. and Erlich D.C., "Biaxial strain deformation and fracture of polymers", Shock Compression of Condensed Matter, 1991 (S.C. Schmidt, R.D. Dick, J.W. Forbes and D.G. Tasker - eds., Elsevier Science Publishers, 1992) pp. 567-570.

7. Weirick L.J., "Shock characterization of epoxy-42 volume per cent. microballoons", Shock Compression of Condensed Matter, 1991 (S.C. Schmidt, R.D. Dick, J.W. Forbes and D.G. Tasker - eds., Elsevier Science Publishers, 1992) pp. 99-102.

8. Nahme H., Hohler V. and Stilp A., "Elastic-plastic behaviour of shock-loaded $\mathrm{FeO}_{-} \mathrm{SiO}_{2}$ composite material", Shock Compression of Condensed Matter, 1991 (S.C. Schmidt, R.D. Dick, J.W. Forbes and D.G. Tasker - eds., Elsevier Science Publishers, 1992) pp. 435-438.

9. Bushman A.V., Kanel G.I., Ni A.L. et al., High Temperature Physics and Dynamics of Intense Pulse Influence, (Chernogolovka, 1988) pp. 22-24.

10. Barker L.M. and Hollenbach R.R., J. Appl. Phys. 43 (1972) 4669-4675.

11. Shuler K.W., J. Mech. Phys. Solids 18 (1970) 277-282.

12. Handbook on Plastics (V.M. Kataev - ed., Moscow, Chemistry, 1975), (in Russian).

13. Nesterenko B.F., Pulse Loading of Heterogeneous Materials (Moscow, Science, 1992), (in Russian). 